\title{
Daño Cardiaco en Ratones Ovariectomizados y Experimental- mente Infectados con Trypanosoma cruzi
}

\author{
Myocardial Tissue Damage in Ovariectomized Mice and Experimentally \\ INFECTED WITH Trypanosoma cruzi
Julio Larenas Herrera' ${ }^{1,3}$, Belén Bello González', Claudio Zúñiga Marti', María Teresa Paláu Castaño ${ }^{2}$, Ulises Vergara Castillo ${ }^{1,4}$

\section{Resumen}

En el presente trabajo se evaluó el daño tisular en el miocardio de ratones hembras $\mathrm{Balb} / \mathrm{c}$ ovariectomizadas y no ovariectomizadas y su relación con el número de seudoquistes y células inflamatorias mononucleares, y su asociación con niveles de parasitemia y mortalidad acumulada en el curso de la infección con 2000 tripomastigotes sanguíneos del clon Dm28c de T. cruzi. Las hembras ovariectomizadas mostraron una prepatencia sanguínea de 3 días y niveles de parasitemia más altos $(\mathrm{p}<0.001)$ durante los primeros 9 días pos-infección (p.i.), en comparación con las no ovariectomizadas que presentaron una prepatencia de 5 días. Sin embargo, el nivel máximo de parasitemia alcanzado por las ovariectomizadas $\left(18.09 \times 10^{4} \pm 1.66 \times 10^{4}\right.$ parásitos $\left./ \mathrm{ml}\right)$ a los 11 días p.i. fue más bajo $(\mathrm{p}<0.05)$ que el nivel máximo de $26.03 \times 10^{4} \pm 1.83 \times 10^{4}$ parásitos $/ \mathrm{ml}$, alcanzado por las no ovariectomizadas a los 11 días p.i. El análisis histopatológico mostró una asociación entre el mayor parasitismo intracelular (seudoquistes), el elevado infiltrado inflamatorio mononuclear, la severidad del daño cardiaco y el 100\% de mortalidad alcanzado por las hembras ovariectomizadas a los 21 días p.i., en comparación con los valores menores y el $70 \%$ de mortalidad alcanzado por las hembras no ovariectomizadas en el mismo periodo. Así, las diferencias sexuales en la susceptibilidad o resistencia a la infección no deberían considerarse como una variable más, sino como un factor de riesgo importante en el desarrollo de las enfermedades infecciosas.

Palabras clave: enfermedad de Chagas; cepas de Trypanosoma cruzi; ovariectomía; estudio histopatológico; infiltrado inflamatorio; daño tisular

\footnotetext{
${ }^{1}$ Departamento de Patología Animal, Facultad de Ciencias Veterinarias y Pecuarias, Universidad de Chile, Santiago de Chile, Chile

${ }^{2}$ Escuela de Nutrición, Universidad Autónoma de Chile, Avenida Pedro de Valdivia 425, Providencia, Santiago de Chile, Chile

${ }^{3}$ E-mail: jlarenas@uchile.cl

${ }^{4}$ E-mail: uvergara@uchile.cl
}

Recibido: 11 de octubre de 2016

Aceptado para publicación: 20 de marzo de 2017 
This study aimed to evaluate the damage in the myocardial tissue in ovariectomized and non-ovariectomized Balb/c mice and the relationship with inflammatory damage, number of pseudocysts and correlation with parasitemia levels and mortality after experimental infection with 2000 blood trypomastigotes from clone Dm28c of Trypanosoma cruzi. Results showed a 3-day blood prepatency and higher parasitemia levels $(p<0.001)$ during the first 9 days of infection (p.i.) in ovariectomized females when compared with non-ovariectomized females which showed a 5-day prepatency. However, the maximum parasitemia level reached by the ovariectomized females $\left(18.09 \times 10^{4} \pm 1.66 \times 10^{4}\right.$ parasites/ $\mathrm{ml}$ ) at 11 days p.i. was lower $(\mathrm{p}<0.05)$ than the maximum parasitemia level of $26.03 \times 10^{4} \pm$ $1.83 \times 10^{4}$ parasites $/ \mathrm{ml}$, observed in the non-ovariectomized females at 11 days p.i. The histopathological analysis showed a correlation between the high number of intracellular parasites (pseudocysts), the magnitude of mononuclear inflammatory infiltrate, the severity of cardiac tissue damage and the $100 \%$ mortality reached by the ovariectomized females at 21 days p.i. in comparison with the lower values and the $70 \%$ mortality showed by the non-ovariectomized females in the same period. Sexual-based differences in susceptibility or resistance to infection should not be overlooked as an additional variable but as an important risk factor in the development of infectious diseases.

Key words: Chagas disease; Trypanosoma cruzi strains; ovariectomy; histopathological study; inflammatory infiltrate; tissue damage

\section{INTRODUCCIÓN}

La enfermedad de Chagas, causada por el protozoo flagelado Trypanosoma cruzi, es una afección inflamatoria crónica que causa la muerte de cerca de 50000 personas por año en la región endémica que se extiende desde el sur de Estados Unidos hasta la Patagonia Argentina (Coura y Viñas, 2010; WHO, 2015). T. cruzi se asocia generalmente a la población humana, pero también puede encontrarse en diversas especies animales, tanto silvestres como domésticas (Gürtler y Cardinal, 2015). Así, el parásito puede encontrase de manera natural en perros, gatos, bovinos, cabras, ovejas, conejos, cerdos, equinos y, desde el punto de vista veterinario, se requiere establecer el rol de estas especies en la epidemiología de la enfermedad, así como su papel como reservorios naturales del agente causante de esta compleja zoonosis (Ramírez et al., 2013).
T. cruzi es un parásito de gran variabilidad biológica y genética, de manera tal que una cepa o aislado natural del parásito corresponde a una población heterogénea constituida por varios clones, lo que conduce a diferencias en el comportamiento entre los distintos aislados o linajes, en particular respecto a su virulencia, tropismo tisular y patogenicidad. La diversidad genético-biológica del parásito ha conducido a su clasificación en seis Unidades Discretas de Tipificación (TcI a TcVI), cuyo rol en el desarrollo de las formas clínicas de la enfermedad de Chagas es, en gran parte, desconocido (Zingales et al., 2012). Sin embargo, la evidencia experimental en el modelo murino sugiere que, el curso de la infección y la severidad del daño tisular, es el resultado de una compleja interacción entre las características genéticas y biológicas de la cepa o aislado infectante del parásito (virulencia, patogenicidad, niveles de parasitemia, tropismo tisular, inducción de respuesta inmune, 
resistencia a drogas) y factores propios del hospedero (sexo, edad y el repertorio genético asociado a los mecanismos de respuesta inmune) (Meza et al., 2014).

En la enfermedad de Chagas, el daño tisular que acompaña a la infección con $T$. cruzi es el que conduce finalmente a la presentación de las formas clínicas de la enfermedad (cardiaca, digestiva o mixta) en el curso de la fase crónica, que se prolongará durante toda la vida de los pacientes infectados. En humanos, la cardiomiopatía chagásica es la manifestación clínica más común y severa, que afecta a cerca del $30 \%$ de los pacientes después de varias décadas de infección asintomática y, representa, también, la mayor causa de discapacidad y mortalidad en las áreas endémicas.

En el modelo murino, el daño inflamatorio en el tejido cardiaco es también la manifestación más frecuente y severa de la infección con T. cruzi. Diversos estudios han documentado, tanto en humanos como en especies animales, que las hembras, a diferencia de los machos, muestran una mayor resistencia a la infección con diversos patógenos bacterianos, virales o parasitarios (Klein, 2000). Diversos estudios han documentado esta diferencia de género en la susceptibilidad o resistencia a infecciones producidas por bacterias como Mycobacterium tuberculosis y parásitos como Toxoplasma gondii, Plasmodium sp, Leishmania sp, Schisostoma y Trypanosoma cruzi (Klein, 2000; Nava-Castro et al., 2012; Markle y Fish, 2014).

Basados en estos antecedentes, en el presente trabajo se evaluó el daño cardiaco causado por la infección experimental con el clon Dm28c de T. cruzi en hembras ovariectomizadas de ratones Balb/c, y se evaluó su relación con el daño inflamatorio, número de seudoquistes y eventual asociación con los niveles de parasitemia, así como la mortalidad acumulada en el curso de la infección.

\section{Materiales y Métodos}

\section{Ratones y Parásitos}

Dos grupos de 10 ratones hembras de la cepa Balb/c (ovariectomizadas y no ovariectomizadas), de 12 semanas de edad y peso aproximado de $25 \mathrm{~g}$, fueron infectados con 2000 tripomastigotes sanguíneos del clon Dm28c de Trypanosoma cruzi (Contreras et al., 1988). Los ratones permanecieron en jaulas de plástico, con agua y comida $a d$ libitum, en un ambiente controlado con temperatura promedio de $22^{\circ} \mathrm{C}$.

Los parásitos provenían de ratones Balb/ $\mathrm{c}$, en los cuales el clon Dm28c se mantuvo in vivo, mediante el traspaso semanal de tripomastigotes sanguíneos, en ratones de la Unidad de Mantención de Animales de Experimentación del Laboratorio de Inmunología de la Facultad de Ciencias Veterinarias y Pecuarias de la Universidad de Chile.

\section{Ovariectomía}

Las 20 hembras Balb/c, cuando tuvieron ocho semanas de edad, fueron anestesiadas mediante inyección intraperitoneal de una mezcla de clorhidrato de ketamina $(100 \mathrm{mg} / \mathrm{kg})$ y clorhidrato de xilazina $(10 \mathrm{mg} / \mathrm{kg}$ ) (Sigma-Aldrich) (Gaertner et al., 2008). Diez ratones fueron sometidos a un procedimiento quirúrgico de ovariectomía, mientras que en los 10 restantes se realizó una cirugía simulada, con incisión hasta la cavidad peritoneal, pero sin remoción de los ovarios (grupo control).

\section{Modelo de Infección Experimental}

En ratones Balb/c infectado con cada una de las cepas o del clon Dm8c de T. cruzi se extrajo $0.6 \mathrm{ml}$ de sangre a los ratones infectados mediante punción cardiaca. Los ratones fueron sacrificados utilizando $\mathrm{CO}_{2}$, vía inhalatoria, cumpliendo con las normas bioéticas y de bioseguridad establecidas en 
los Manuales de Normas de Bioética y de Bioseguridad de la Comisión Nacional de Investigación Científica y Tecnológica (CONICYT).

Los procedimientos de infección experimental de ratones, extracción de sangre y extracción de tejidos, luego del sacrificio de los animales, se realizaron en un gabinete de bioseguridad Forma Scientific Class IIA/B3 (EEUU). El manejo adecuado de los animales y el cumplimiento de los protocolos fueron certificados por los comités de Bioética Animal y de Bioseguridad, de la Facultad de Ciencias Veterinarias y Pecuarias de la Universidad de Chile.

La sangre fue colocada en tubos estériles conteniendo $0.1 \mathrm{ml}$ de citrato de sodio como anticoagulante. Se tomó $10 \mu \mathrm{l}$ y se diluyó en $490 \mu 1$ de suero fisiológico estéril, y luego se hizo el recuento de parásitos en la cámara de Neubauer. Una vez determinada la cantidad total de parásitos, se hicieron las diluciones necesarias en suero fisiológico estéril, para obtener 2000 parásitos en $0.2 \mathrm{ml}$. Esta dosis fue inoculada en cada ratón de los grupos experimentales.

Se utilizó, además, como control negativo, un grupo de cinco hembras de 10 semanas de edad, que se inocularon con $0.2 \mathrm{ml}$ de sangre de ratones Balb/c no infectados y diluida de manera similar a la de aquella proveniente de ratones infectados. Estos ratones se sangraron en forma paralela a los grupos infectados para establecer que las alteraciones y eventual muerte de los animales experimentales se debe a la infección con T. cruzi y no a variables, como una eventual anemia provocada por las sucesivas sangrías realizadas durante el desarrollo del estudio.

\section{Estudio de Parasitemia}

Los ratones experimentalmente infectados se sangraron cada dos días a partir del tercer día pos-infección (p.i.) para determi- nar la prepatencia y la eventual variación en el número de parásitos libres en circulación. La sangre se recolectó de la vena caudal en tubos de microhematocrito heparinizados, fue centrifugada a $700 \mathrm{~g}$ por 5 min y se dejó reposar por $30 \mathrm{~min}$ en estufa a $37^{\circ} \mathrm{C}$, para medir el volumen de sangre. Finalmente, cada muestra fue colocada en un portaobjeto para determinar el número de parásitos en 50 campos elegidos al azar, utilizando un aumento de 400X. Los resultados se expresaron como el promedio y desviación estándar de parasitemia del grupo, de acuerdo al método descrito por De Arias y Ferro (1988). La determinación de los niveles de parasitemia se realizaron hasta obtener muestras negativas o hasta la muerte de los ratones.

\section{Estudio Histopatológico}

El daño histopatológico, presencia de seudoquistes y el infiltrado de células mononucleares se determinó en muestras de tejido cardiaco de ratones de ambos grupos. Se sacrificó un ratón por grupo los días 7, 14 y 21 p.i. Los corazones fueron cortados sagitalmente de la base al vértice, lo que incluyó parte del ventrículo izquierdo, septo interventricular y atrio izquierdo. Los tejidos fueron fijados en Bouin-formalina $10 \%$ e incluidos en parafina (López et al., 1982). Se hicieron cortes de $5 \mu \mathrm{m}$ que fueron teñidos con hematoxilina-eosina.

Se determinó la severidad y características del daño tisular (presencia de focos inflamatorios, hiperemia, edema, hemorragia, fibrosis, necrosis, cambios degenerativos), utilizando un aumento de 200X. Se cuantificó el número de seudoquistes parasitarios y el número de células mononucleares en 50 campos elegidos al azar (400X).

La captura y digitalización de imágenes se realizó utilizando el programa Motic MC Camera 2.0, y la cuantificación de células se determinó utilizando el Programa Image J 1.48 (National Institute of Health, EEUU). 


\section{Análisis Estadístico}

Los resultados de los niveles máximos de parasitemia, número de células inflamatorias mononucleares y número de seudoquistes, se analizaron mediante un análisis de varianza. El cálculo de mortalidad/supervivencia incluye los animales muertos como consecuencia de la infección con $T$. cruzi y los sacrificados los días 7, 14 y 21 p.i. El análisis de supervivencia se realizó de acuerdo al método de Kaplan y Meier (1958), utilizando en ambos casos el programa Graph Pad Prism v. 5.0.

\section{Resultados}

\section{Niveles de Parasitemia y Mortalidad}

En la Figura 1 se muestra la evolución de los niveles de parasitemia (1a) y del porcentaje de supervivencia (1b) como expresión del desarrollo de la infección en las hembras Balb/c experimentalmente infectadas con el clon Dm28c de T. cruzi. El periodo de prepatencia sanguínea fue de 3 días para las hembras ovariectomizadas y de 5 días para las hembras no ovariectomizadas (Figura 1a). Los niveles de parasitemia fueron significativamente más altos $(\mathrm{p}<0.001)$ en las hembras ovariectomizadas, durante los primeros 9 días de la infección. Sin embargo, el nivel máximo de parasitemia alcanzado por las hembras ovariectomizadas $\left(18.09 \times 10^{4} \pm\right.$ $1.66 \times 10^{4}$ parásitos $/ \mathrm{ml}$ ) a los 11 días p.i. resultó significativamente más bajo $(\mathrm{p}<0.05)$ que el nivel máximo de $26.03 \times 10^{4} \pm 1.83 \times 10^{4}$ parásitos/ml alcanzado por las hembras normales no ovariectomizadas a los 11 días p.i.

Las hembras ovariectomizadas presentaron $100 \%$ de mortalidad acumulada al día 21 p.i., mientras el grupo control fue de $70 \%$. El 30\% de las hembras del grupo control no ovariectomizado sobrevivió más allá de los 3 meses p.i.

\section{Estudio Histopatológico}

En el día 7 p.i. se encontró mayor evidencia de focos de infiltrado inflamatorio (Figura 4), necrosis tisular y presencia de algunos seudoquistes en las hembras ovariectomizadas infectadas (Figura 2B), en comparación con las hembras no ovariectomizadas infectadas (Figura 2A).

En el día 14 p.i., el tejido cardiaco mostró algunos seudoquistes y lesiones degenerativas y necróticas, que fueron más marcadas en las hembras ovariectomizadas (Figura 2D) que en las no ovariectomizadas (Figura 2C).

En el día 21 p.i. se detectaron lesiones inflamatorias focalizadas, numerosos seudoquistes y severa infiltración celular (Figura 2E), mientras que en el tejido de las hembras ovariectomizadas se observaron procesos necróticos severos y diseminados, mayor número de seudoquistes y elevado número de células inflamatorias mononucleares (Figura $2 \mathrm{~F}$ ).

En el grupo control de hembras no ovariectomizadas y no infectadas con $T$. cruzi no se encontraron alteraciones o daño cardiaco en los animales sacrificados en los días 7, 14 y 21 pos-inoculación con sangre de ratones Balb/c no infectados.

En la Figura 3 se muestra la evolución del número de seudoquistes. Las hembras ovariectomizadas presentaron un mayor número de seudoquistes y de células inflamatorias mononucleares $(\mathrm{p}<0.0001)$, luego de la infección experimental con el clon Dm28c de T. cruzi. Asimismo, en la Figura 4 se muestra la evolución del infiltrado inflamatorio en el tejido cardiaco de las hembras infectadas ovariectomizadas y no ovariectomizadas. 

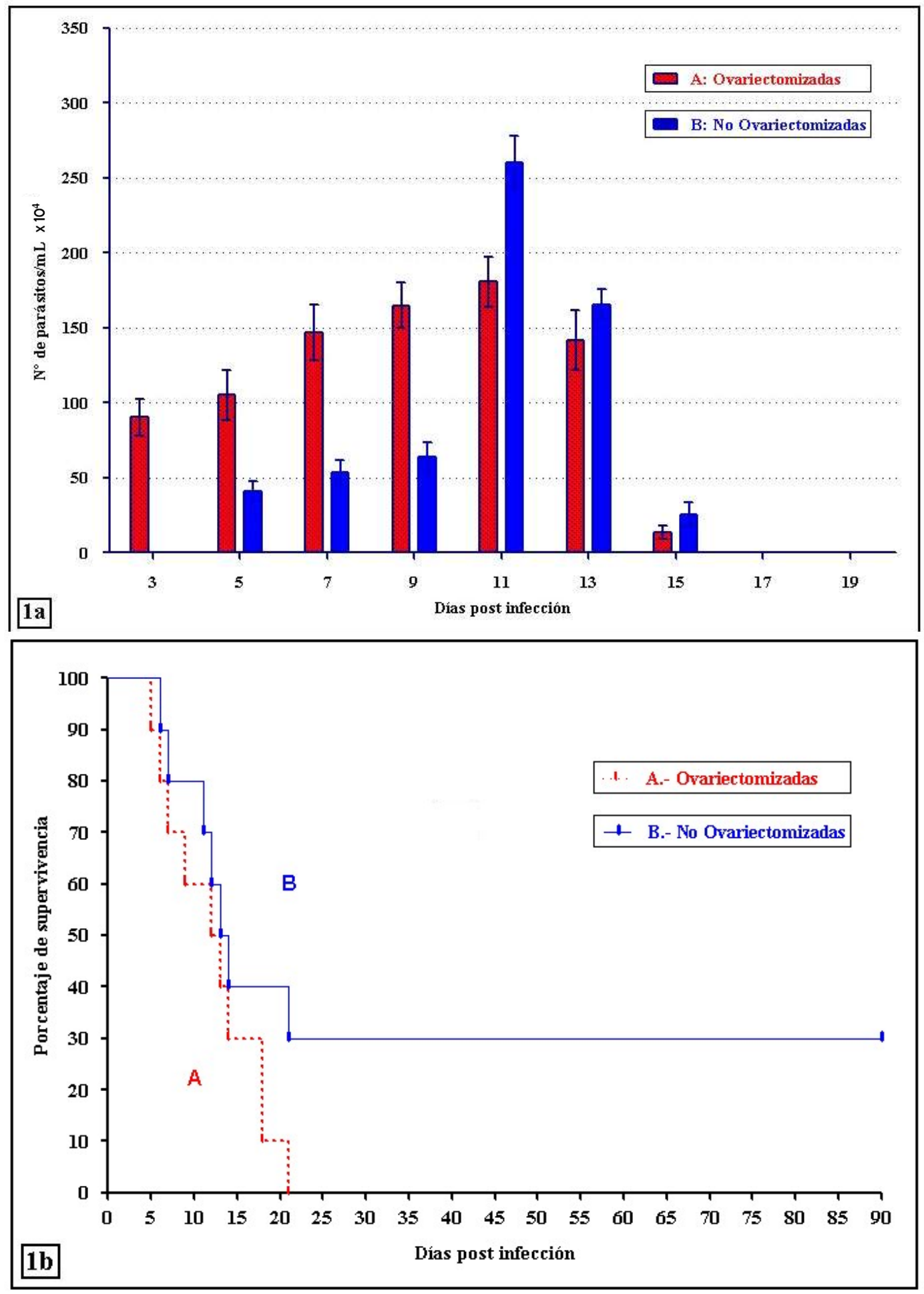

Figura 1. Evolución de los niveles de parasitemia (1a) y de supervivencia (1b) en ratones Balb/ c hembras ovariectomizadas y no ovariectomizadas, infectadas con 2000 tripomastigotes sanguíneos del clon Dm28c de T. cruzi 

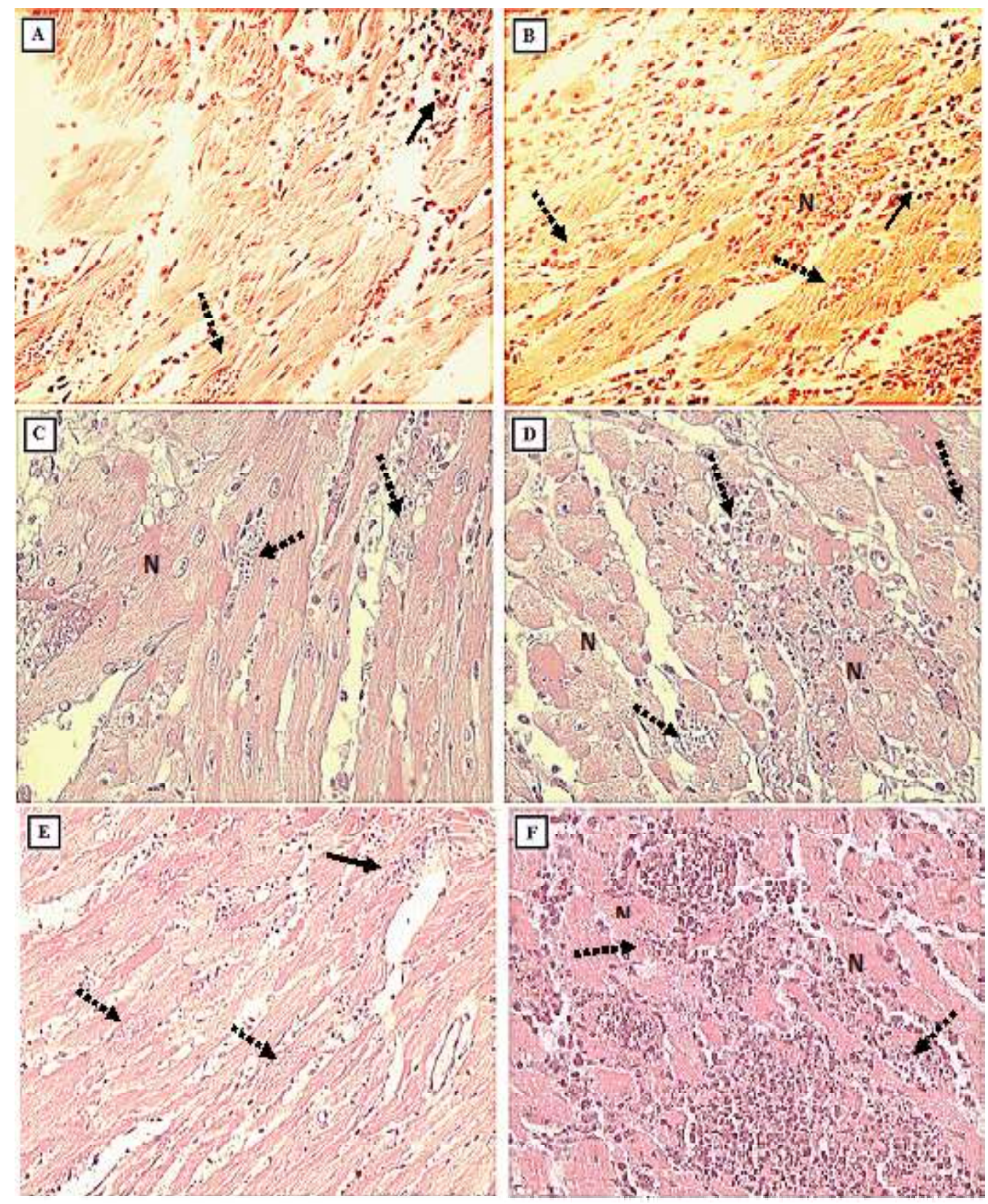

Figura 2. Evolución del daño inflamatorio en el tejido cardiaco de hembras control negativo (no ovariectomizadas) (A, C, E) y de hembras ovariectomizadas (B, D, F) en los días 7, 14 y 21 pos-infección con 2000 tripomastigotes sanguíneos del clon Dm28c de T. cruzi. A, B: En el día 7 p.i. se muestran focos de infiltración de células inflamatorias (flecha continua), necrosis del tejido muscular $(\mathrm{N})$ y algunos seudoquistes (flechas segmentadas), lo que fue más evidente en ratones ovariectomizados. C, D: En el día 14 p.i. se observan lesiones degenerativas y necróticas $(\mathrm{N})$ junto con presencia de algunos seudoquistes (flechas segmentadas). Las lesiones y la cantidad de seudoquistes son más marcados en los animales ovariectomizados infectados. E, F: En el día 21 p.i., el tejido cardiaco del grupo control no ovariectomizado mostró evidencia de lesiones focales con degeneración leve y escasa respuesta inflamatoria (flecha continua) en relación a las marcadas lesiones de carácter necrótico $(\mathrm{N})$ y presencia de seudoquistes (flechas discontinuas) de los animales ovariectomizados. 


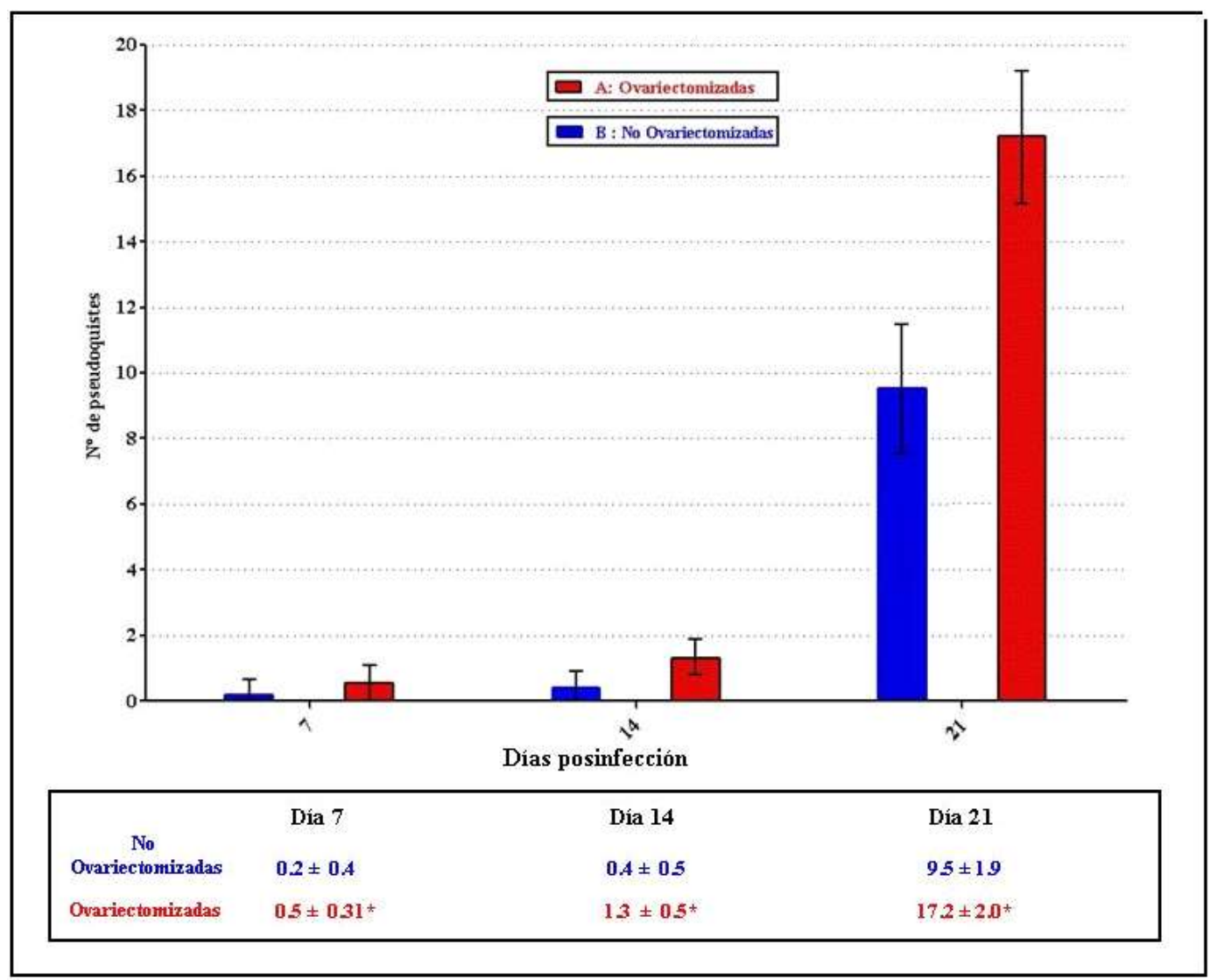

Figura 3. Evolución del número de seudoquistes en el tejido cardiaco de ratones hembras Balb/c ovariectomizadas y no ovariectomizadas infectadas con el clon Dm28c de T. cruzi. Superíndices $(*)$ indican diferencia estadística $(\mathrm{p}<0.0001)$ entre grupos dentro de día pos-infección

\section{Discusión}

Los resultados de este estudio muestran un aumento de los niveles de parasitemia, elevado número de seudoquistes, mayor número de células inflamatorias mononucleares, severo daño cardiaco y mayor mortalidad en las hembras Balb/c ovariectomizadas en comparación con las hembras no ovariectomizadas infectadas con 2000 tripomastigotes sanguíneos del clon Dm28c de T. cruzi. Estos resultados están en concordancia con la sugerencia que el parasitismo intracelular y el daño tisular producido por el infiltrado inflamatorio mononuclear que acompaña a la infección dependen, no solo del repertorio genético del hospedero y de características biológicas como la virulencia y patogenicidad del parásito, sino también de factores como las hormonas ováricas. Los estrógenos parecen modular la función de las células del sistema inmune, determinando una mayor resistencia a la infección en las hembras enteras (Roberts et al., 2001; Markle y Fish, 2014).

El efecto de los estrógenos sobre las células del sistema inmune es mediado fundamentalmente por receptores intracelulares y de membrana (Schneider, 2014) que pueden encontrarse en linfocitos T, linfocitos B, 


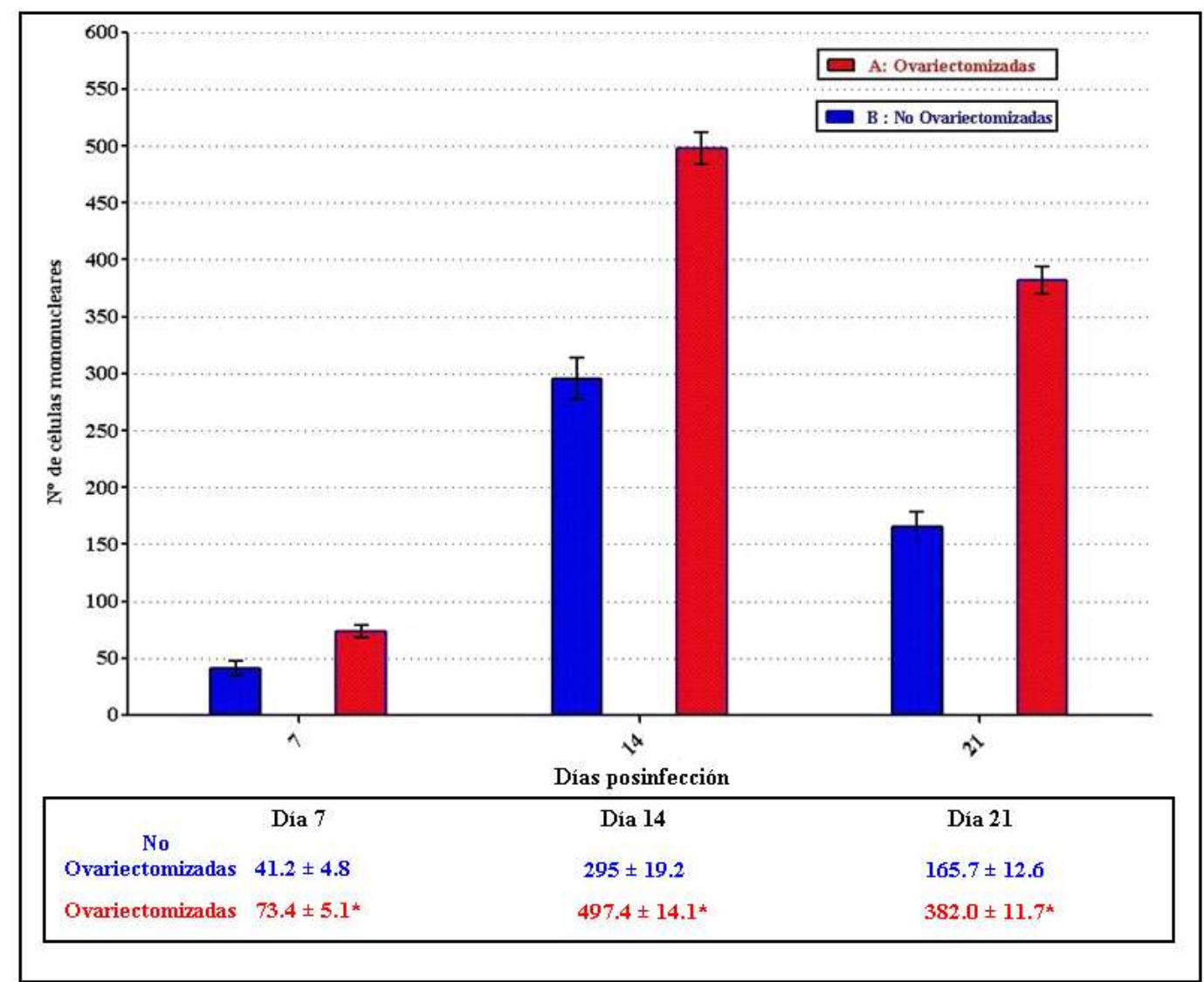

Figura 4. Evolución del infiltrado mononuclear en el tejido cardiaco de ratones hembras Balb/c ovariectomizadas y no ovariectomizadas infectadas con el clon Dm28c de T. cruzi. Superíndices $(*)$ indican diferencias estadísticas $(\mathrm{p}<0.0001)$ entre grupos dentro de día pos-infección

células dendríticas, monocitos, macrófagos, neutrófilos, células NK, células del estroma tímico, células progenitoras mieloides y otras células de la médula ósea (Kovats, 2015; Klein y Flanagan, 2016). Los complejos estrógeno-receptor intracelular son translocados al núcleo donde funcionan como reguladores transcripcionales de genes que contienen elementos de respuesta a estrógenos (EREs) en sus promotores o pueden interactuar con otros factores de transcripción como NF- $\kappa \mathrm{B}$, que modulará la expresión de genes que no contienen EREs. En algunos casos, receptores no clásicos para estrógenos que se expresan en la membrana plasmática, pueden amplifi- car la cascada de señales de activación en las células del sistema inmune (Gubbels Bupp, 2015).

Los niveles fisiológicos de los estrógenos, que son relativamente bajos, parecen promover una respuesta Th1 y la producción de interferón gamma (IFN- $\gamma$ ) y otros mediadores proinflamatorios. Sin embargo, en niveles más altos o supra-fisiológicos, los estrógenos estimulan una respuesta $\mathrm{Th} 2$, la producción de IL4 y el desarrollo de linfocitos $T$ reguladores, que inhiben la respuesta proinflamatoria, tanto de la inmunidad innata como de la inmunidad adquirida (Kovats, 2015). 
La mayor respuesta immune celular y humoral a la infección de las hembras y la compleja interacción de los factores que contribuyen a este fenómeno no está claramente establecida, pero parece incluir no solo las hormonas sexuales, sino también, diferencias sexuales de origen genético, debido a la presencia de un segundo cromosoma $\mathrm{X}$, o factores epigenéticos como RNAs de interferencia, metilación del DNA y modificación de histonas, cuya expresión parece también regulada por los niveles de las hormonas sexuales (Markle y Fish, 2014). Aunque uno de los dos cromosomas X es inactivado en las hembras, esta inactivación no es completa y cerca del $15 \%$ de los genes codificados en el segundo cromosoma X escapan a la inactivación en la mujer (Carrel y Willard, 2005). Este escape de la inactivación conduce a la sobreexpresión de algunos genes ligados al cromosoma X y que codifican la expresión de proteínas asociadas al sistema inmune como la molécula coestimuladora CD40, el factor de transcripción Foxp3, que se expresa en linfocitos $\mathrm{T}$ reguladores, receptores para citoquinas como IL-2RG, IL9R, receptores para quimioquinas (CXCR3) y receptores Toll (TLR7, TLR8 y TLR9), que se expresan en células de la inmunidad innata y reconocen ácidos nucleicos de agentes infecciosos. El cromosoma X contiene, además, los genes de una serie de pequeños RNA de interferencia (miRNA) no codificantes, que actúan como reguladores postranscripcionales de la expresión génica. Algunos de estos miRNAs están involucrados en la diferenciación y funcionamiento de diversas células del sistema inmune y su expresión parece encontrarse bajo el rol regulador de hormonas ováricas (Khan et al., 2015).

Estos antecedentes permiten sugerir que la mayor susceptibilidad a la infección con el clon Dm28c de T. cruzi que se observa en las hembras ovariectomizadas, puede obedecer a la baja expresión de genes asociados a la respuesta inmune que se encuentran bajo el efecto modulador de las hormonas ováricas (Jansen et al., 2014). Así, las diferencias sexuales en la susceptibilidad o resistencia a la infección no deben considerarse como una variable más, sino como un factor de riesgo importante en el desarrollo de las enfermedades infecciosas. Este aspecto es particularmente importante en relación a los perros que, junto a los gatos y roedores, son los principales hospederos de T. cruzi en los hábitats domésticos y peridomésticos (Ramírez et al., 2013; Gürtler y Cardinal, 2015).

La mayor susceptibilidad a la infección con el parásito de las hembras ovariectomizadas puede constituir una señal de alerta para las estrategias de gonadectomía orientadas a controlar la población de perros abandonados en las áreas urbanas de la regiones endémicas, y que pueden convertirse en una factor de riesgo importante en la transmisión de T. cruzi a humanos u otros hospederos mamíferos; en especial, si se considera la evidencia que muestra la presencia del parásito en la saliva y orina de los animales infectados (Marsden y Hagstrom, 1966; Lopes et al., 1991) y que los perros pueden infectarse a través de la ingestión de triatominos infectados, así como por la ingestión de alimentos y agua contaminadas con deposiciones de insectos infectados o con la mordedura de perros u otros mamíferos infectados (Gürtler y Cardinal, 2015).

\section{Conclusiones}

Se observó una asociación entre la presencia de seudoquistes, la magnitud del infiltrado inflamatorio mononuclear, la severidad del daño en el tejido cardiaco y la mortalidad de ratones $\mathrm{Balb} / \mathrm{c}$ hembras ovariectomizadas e infectadas con 2000 tripomastigotes sanguíneos del clon Dm28c de T. cruzi.

\section{Agradecimientos}

Este estudio ha sido financiado por los proyectos DPA15LIHBAC15001 y DPA15LIHBAC15002, Departamento de Patología Animal, Facultad de Ciencias Veterinarias y Pecuarias, Universidad de Chile. 


\section{Literatura Citada}

1. Carrel L, Willard HF. 2005. Xinactivation profile reveals extensive variability in $\mathrm{X}$-linked gene expression in females. Nature 434: 400-404. doi: 10.1038/nature03479

2. Contreras VT, Araujo-Jorge TC, Bonaldo MC, Thomaz N, Barbosa HS, Meirelles MSL, Goldenberg S. 1988. Biological aspects of the Dm28c clone of Trypanosoma cruzi after metacyclogenesis in chemically defined media. Mem Inst Oswaldo Cruz 83: 123-133. doi: 10.1590/S0074-02761988000100016

3. Coura JR, Viñas PA. 2010. Chagas disease: a new worldwide challenge. Nature 465: S6-S7. doi: 10.1038/ nature09221

4. De Arias AR, Ferro EA. 1988. Quantification of Trypanosoma cruzi parasitemia by direct micromethod. Trans R Soc Trop Med Hyg 82: 248.

5. Gaertner DJ, Hallman TM, Hankenson FC, Batchelder MA. 2008. Anesthesia and analgesia for laboratory rodents. In: Anesthesia and analgesia in laboratory animals. San Diego, USA: Academic Press. p 256-260.

6. Gubbels Bupp MR. 2015. Sex, aging, immune system and chronic disease. Cell Immunol 294: 102-110. doi: 10.1016/ j.cellimm.2015.02.002

7. Gürtler RE, Cardinal MV. 2015. Reservoir host competence and the role of domestic and commensal hosts in the transmission of Trypanosoma cruzi. Acta Trop 151: 32-50. doi: 10.1016/ j.actatropica.2015.05.029

8. Jansen R, Batista S, Brooks AI, Tischfield JA, Willemsen G, van Grootheest G, Hottenga JJ, et al. 2014. Sex differences in the human peripheral blood transcriptome. BMC Genomics 15:33. doi: 10.1186/1471-2164-15-33
9. Kaplan E, Meier P. 1958. Nonparametric estimation from incomplete observations. J Am Stat Assoc 53: 457-481. doi: 10.2307/2281868

10. Khan D, Dai R, Ahmed SA. 2015. Sex differences and estrogen regulation of miRNA in lupus, a prototypical autoimmune disease. Cell Immunol 294: 70-79. doi: 10.1016/j.cellimm.2015. 01.004

11. Klein S. 2000. The effects of hormones on sex differences in infection: from genes to behavior. Neurosci Behav Rev 24: 627-638. doi: 10.1016/S01497634(00)00027-0

12. Klein S, Flanagan KL. 2016. Sex differences in immune response. Nat Rev Immunol 16: 626-638. doi: 10.1038/ nri.2016.90

13. Kovats S. 2015. Estrogen receptors regulate innate immune cells and signaling pathways. Cell Immunol 294: 63-69. doi: 10.1016/j.cellimm.2015. 01.018

14. López M, Leyton C, Graf M. 1982. Técnicas de histología y citología. $2^{\mathrm{a}} \mathrm{ed}$. Chile: Facultad de Medicina, Universidad de Chile. 242 p.

15. Lopes RA, Ribeiro RD, Carvalho TL, de Albuquerque S, Watanabe IS. 1991. Presence of amastigotes in the Weber's lingual salivary gland of Trypanosoma cruzi-infected mice. Braz Dent J 2: 75-79.

16. Markle JH, Fish EN. 2014. SeXX matters in immunity. Trends Immunol 35: 97-104. doi: 10.1016/j.it.2013.10.006

17. Marsden PD, Hagstrom JWC. 1966. Trypanosoma cruzi in the saliva of beagle puppies. Trans R Soc Trop Med Hyg 60: 189-191. doi: 10.1016/00359203(66)90026-5

18. Meza, SKL, Kaneshima EN, Silva SO, Gabriel, M, de Araujo, SM, Gomes, ML, Monteiro WM, et al. 2014. Comparative pathogenicity in Swiss mice of Trypanosoma cruzi IV from northern Brazil and Trypanosoma cruzi II from 
southern Brazil. Exp Parasitol 146: 34 42. doi: 10.1016/j.exppara.2014.08.014

19. Nava-Castro K, Hernandez-Bello R, Muñiz-Hernandez S, Camacho-Arroyo I, Morales-Montor J. 2012. Sex steroids, immune system, and parasitic infections: facts and hypotheses. Ann N Y Acad Sci 1262: 16-26. doi: 10.1111/ j.1749-6632.2012.06632.x

20. Ramírez JD, Turriago B, Tapia-Calle G, Guhl F. 2013. Understanding the role of dogs (Canis lupus familiaris) in the transmission dynamics of Trypanosoma cruzi genotypes in Colombia. Vet Parasitol 196: 216-219. doi: 10.1016/j.vetpar.2012.12.054

21. Roberts $C W$, Walker W, Alexander J. 2001. Sex-associated hormones and immunity to protozoan parasites. Clin Microbiol Rev 14: 476-488. doi: 10.1128/ CMR.14.3.476-488.2001
22. Schneider AE, Kárpáti E, Schuszter K, Tóth EA, Kiss E, Kulcsár M, László G, Matko J. 2014. A dynamic network of estrogen receptors in murine lymphocytes: fine-tuning the immune response. J Leukoc Biol 96: 857-872. doi: 10.1189/jlb.2A0214-080RR

23. WHO 2015. Chagas disease in Latin America: an epidemiological updated based on 2010 estimates. Wkly Epidemiol Rec 90: 33-44.

24. Zingales B, Miles MA, Campbell DA, Tibayrenc M, Macedo AM, Teixeira MMG, Schijman AG, et al. 2012. The revised Trypanosoma cruzi subspecific nomenclature: rationale epidemiological relevance and research applications. Infect Genet Evol 12: 240-253. doi: 10.1016/j.meegid.2011.12.009 